\title{
An unexpected association in a patient with heart failure presenting a surgical challenge
}

\author{
Sofia Alegria $\mathrm{MD}^{1}{ }^{1}$ ( $\mid$ Otília Simões $\mathrm{MD}^{1}$ | Ana Rita Almeida $\mathrm{MD}^{1}$ | \\ João Silva e Castro $\mathrm{MD}^{2}$ | Álvaro Laranjeira $\mathrm{MD}^{3}$ | Hélder Pereira MD, PhD ${ }^{1}$
}

${ }^{1}$ Department of Cardiology, Hospital Garcia de Orta, Almada, Portugal

${ }^{2}$ Department of Vascular Surgery, Hospital de Santa Marta, Lisboa, Portugal

${ }^{3}$ Department of Cardiovascular Surgery, Hospital de Santa Marta, Lisboa, Portugal

\section{Correspondence}

Sofia Alegria, Serviço de Cardiologia, Hospital Garcia de Orta, Av. Torrado da Silva,

2801-951 Almada, Portugal.

Email: asofia.alegria@gmail.com

\begin{abstract}
Bicuspid aortic valve (BAV) is the most common form of congenital heart disease and frequently leads to premature valvular dysfunction. BAV is associated with aortic wall abnormalities and a high prevalence of ascending aorta dilatation and coarctation of the aorta (COA). Consequently, in patients with BAV a careful assessment of the valve, and also of the aortic root and the ascending aorta, should be performed. The most feared complication is aortic dissection, however, the actual incidence of this complication is low. We report the case of a 58-year-old man who presented with New York Heart Association class III heart failure. The work-up revealed BAV with severe stenosis and severe compromise of left ventricle systolic function. In addition, $\mathrm{CoA}$ in the isthmus region, and type $\mathrm{B}$ dissection of the aorta were diagnosed.

KEYWORDS

aortic dissection, bicuspid aortic valve, coarctation of the aorta, heart failure
\end{abstract}

Bicuspid aortic valve (BAV) is the most common form of congenital heart disease $(0.5-2 \%)^{1}$ and is associated with aortic wall abnormalities, including ascending aortic dilatation and coarctation of the aorta (CoA), probably due to a common underlying developmental defect involving the aortic valve and the aortic wall. Consequently, in patients with BAV a careful assessment of the valve, and also of the aortic root and the ascending aorta, should be performed. ${ }^{2}$ The most feared complication is aortic dissection, however, the actual incidence of this complication is low (4\%). 3,4

We report the case of a 58-year-old man with a history of a "cardiac murmur" since adolescence.

He was asymptomatic until 1 month before admission when New York Heart Association class III heart failure developed.

Transthoracic echocardiogram showed BAV with severe stenosis; with a left ventricle ejection fraction of $12 \%$. Computed tomography angiography (angio-CT) showed severe CoA in the isthmus region, associated with extensive collateral circulation, aneurysm of the descending aorta, and dissection of the aorta after the coarctation extending up to the left common iliac artery (Figure $1 \mathrm{~A}$ and $\mathrm{B}$ ).

After heart team discussion the patient was submitted to a twostep procedure, first with physiological correction of the CoA with a bifurcated extra-anatomical conduit from the ascending aorta to the common femoral arteries, through a sub-aponeurotic tunnel in the anterior abdominal wall (Figure $1 \mathrm{C}$, arrowhead). Afterward, it was safe to start the patient on cardiopulmonary bypass and aortic valve replacement with a bioprosthesis was performed (Figure 1C, arrow). The postoperative course was uneventful (Figure 1D, postoperative angio-CT) and after 3 years of follow-up, the patient remains free of clinical events.

\section{AUTHOR CONTRIBUTIONS}

OS and ARA conceived and designed the study. SA, OS, ARA, JSC, and $\mathrm{AL}$ collected the data. SA, OS, ARA, and $\mathrm{AL}$ analyzed and 


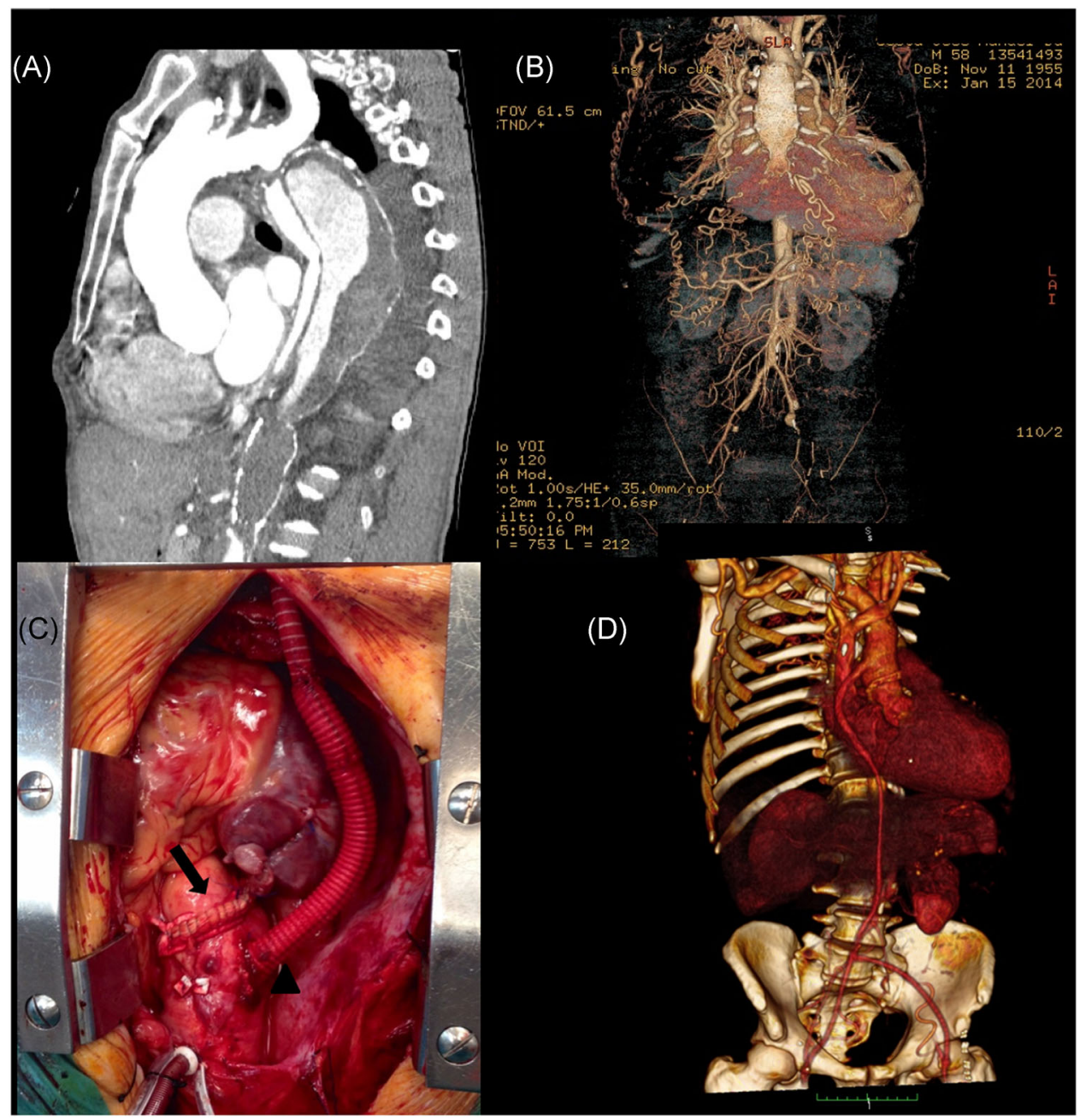

FIGURE 1 A, Sagital reconstruction of the angio-CT demonstrating severe coarctation of the aorta in the isthmus region and aneurysmatic dilatation and dissection of the descending aorta postcoarctation; $\mathrm{B}$, coronal reconstruction of angio-CT showing extensive collateral circulation; C, intraoperative image after aortic valve replacement with a bioprosthesis (arrow) and implantation of the extra-anatomical conduit in the ascending aorta (arrowhead); D, coronal reconstruction of angio-CT showing the bifurcated extra-anatomical conduit extending from the ascending aorta to the common femoral arteries. angio-CT, computed tomography angiography

interpreted the data. SA drafted the article. OS, ARA, and HP critically revised the article. SA, OS, ARA, JSC, AL, and HP approved the article.

\section{ORCID}

Sofia Alegria (D) http://orcid.org/0000-0002-8745-3541

\section{REFERENCES}

1. Abdulkareem N, Smelt J, Jahangiri M. Bicuspid aortic valve aortopathy: genetics, pathophysiology and medical therapy. Interact Cardiovasc Thorac Surg. 2013;17:554-559.
2. Cecconi M, Nistri S, Quarti A, et al. Aortic dilatation in patients with bicuspid aortic valve. J Cardiovasc Med. 2006;7(1):11-20.

3. Evangelista A. Bicuspid aortic valve and aortic root disease. Curr Cardiol Rep. 2011;13(3):234-241.

4. Samiei N, Alizadeh A, Hashemi A, Mirmesdagh Y, Mozaffari K, Hosseini S. Unusual case of aortic coarctation complicated by mycotic pseudoaneurysm and bicuspid aortic valve endocarditis. Res Cardiovasc Med. 2014;3(1):e13838.

How to cite this article: Alegria S, Simões O, Almeida AR, Silva e Castro J, Laranjeira Á, Pereira H. An unexpected association in a patient with heart failure presenting a surgical challenge. J Card Surg. 2020;35:431-432. https://doi.org/10.1111/jocs.14393 